\title{
Enrichment of Se in Soil-Crop Systems in the Selenium-rich Region and their Effects for the Enrichment of Heavy Metals
}

\author{
ShanHu Hua, ShengXuLuob, YuJie Xiao, Zhang Luo, ChunLei Fan
}

Key Laboratory of Tropical Biological Resources for Ministry of Education, College of Materials and Chemical Engineering, Hainan University, Haikou, 570228, China

a215121256@qq.com, ${ }^{\mathrm{b} C}$ Corresponding author, shxlu0525@126.com

\begin{abstract}
KEYWORD: selenium-rich soil;crops; distribution of Se;enrichment of heavy metals;effects of Se ABSTRACT: 36 kinds of crops and the planting soils had been treated as research samples. All the materials came from Nandu river basin selenium-rich region. 120 research samples had been chosen to research the distribution of selenium and their effects on enrichment of heavy metals in selenium-rich regions. The results showed that the amount of selenium (based on fresh weight) are of the following order: grain and oil species $>$ leaf vegetable species $>$ potato species $>$ bean species $>$ melon and fruit species. The parameter order (BCF) of selenium enrichment (from high to low) was leaf vegetable species $\geq$ potato species $>$ grain and oil species $>$ melon and fruit species $\geq$ bean species; Based on the standard of the amount of selenium that the selenium-rich food has, leaf vegetable species should be the optimal crops for developing among all these species; $\mathrm{Pb}$ and $\mathrm{Cd}$ show associated effect with Se in selenium-rich soil, the associated effect between $\mathrm{Se}$ and $\mathrm{Cd}$ was significant. Selenium-rich soil shows no significant effects on the enrichment of heavy metals in crops, it showed antagonism effect to $\mathrm{Pb}$ and synergistic effect to $\mathrm{Cd}$.
\end{abstract}

\section{INTRODUCTION}

Se is the necessary element to human beings. It has important physiology functions. Se deficiency can cause diseases like endemic disease, cardiovascular disease. From northeast to southwest China, there are 15 provinces considered as "Se lack region", selenium deficiency is widespread in those regions ${ }^{[1]}$. The selenium rich soil region in Hainan province is 9545 square kilometers that covered $28 \%$ of the whole island, the relative value and definite value are both the highest in China. If Hainan relies on abundant selenium-rich land resources to develop selenium-rich crops, it will be of important practical significance for improving the health status of the regions with selenium deficiency. At the same time Se shows strong affinity with metals. This effect on one hand would accelerate $\mathrm{Cd}$ and $\mathrm{Pb}$ enrichment, this could bring the pollution risk to the crops ${ }^{[2]}$; On the other hand, the Se in the system of soil-crops could change the speciation of heavy metals and impact the enrichment of heavy metals for soil-crops ${ }^{[3]}$. Therefore, to elucidate the Se distribution of soil-crops in selenium-rich region and to explore the effects of the distribution of Se on heavy metal enrichment have great theoretical and practical values in the exploitation of selenium enrichment soil.

The key to develop the selenium-rich agriculture products is to select the crops which show great selenium enrichment ability. The typical selenium-rich soil in Nandu river basin had been selected as research object. 36 kinds of crops and planting soils had been gathered to explore the distribution of Se in soil-crops system and to find the kinds of crops which can easily enrich Se. Also, the effects of Se on the enrichment of typical heavy metals $(\mathrm{Cd}$ and $\mathrm{Pb})$ by crops had been discussed.

\section{Materials and methods}

\section{Sample gathering}

36 kinds of crops had been gathered from typical selenium enrichment area along Nandu river basin, including Zuntan, Meirenpo, Rennan, Longhe, Shanshangshan, etc. The crops are cabbage, brassica juncea, ipomoea batatas leaves, brassica pekinensis, brassicachinensis L, the emperor cuisine, garlic bolt latin, allium fistulosum, allium chinense, sechium edule, zucchini, cucurbita moschata, cucumber, papaya, water melon, solanum melongena, pao chilli, Banana, tomatoes, kidney bean, vigna unguiculata, glycine max, cassava, taro roots, white Radish, daucus carota, 
oryzasativa, corn, sesamum indicum. The farmland which crops grew on had been treated as research objects. By using Latitude and longitude of each field to indicate their position for the sampling units, a total of 120 sample units drawn from the crops field were used for the experiment.5-7 sampling points of the eatable part of crops and the planting soil $(0-20 \mathrm{~cm})$ in every sample unit were identified using statistical method, using multi-sampling mixing as a representative sample of the sample unit.

\section{Sample preparation}

Soil: The soil sample was around $1 \mathrm{~kg}$ and it was mixed evenly. It had been separated using quartation to $500 \mathrm{~g}$. The soil had been spread out on the plastic film, drought with wind for a week, until it would not adhere to the hand. In this process, the soil was crashed, the stone and decaying branches and withered leaves had been get rid of. It then got smashed and reduced to analyzing sample. The sample then milled with agate grinding mill until all passing 80 sieve mesh.

Crops: the collected crops had been washed with tap water, distilled water, ultrapure water respectively. Crops were drought in the air and then in the drying oven in $60^{\circ} \mathrm{C}$ until constant weight. Finally, the samples were smashed until passing the 40 sieve mesh.

\section{Determination of Se content of samples}

Soil sample digestion: $0.2 \mathrm{~g}$ pre-treatmentsoil sample were put in microwave digestion tank, $8 \mathrm{~mL}$ $\mathrm{HNO}_{3}$ were added, pre-digested for $3 \mathrm{~h}$, then the digestion process used microwave digestion instrument. After the digestion process completed, at $150^{\circ} \mathrm{Cwaited}$ until it nearly desiccated, then added ultrapure water until the volume was $25 \mathrm{~mL}$.

Crops sample digestion: $0.2 \mathrm{~g}$ pre-treatment crops sample were put in microwave digestion tank, $8 \mathrm{~mL} \mathrm{HNO}_{3}$ was added, pre-digested for $3 \mathrm{~h}$, then the digestion process were conducted by using microwave digestion instrument. After the digestion process completed, added $2 \mathrm{~mL} \mathrm{H}_{2} \mathrm{O}_{2}$, at $150^{\circ} \mathrm{C}$ waited until it nearly desiccated, then added ultrapure water until the volume was $25 \mathrm{~mL}$.

Method: Se had been measured with ICP-MS (model NexIONTM300), the instrument working condition were optimized with Nexion setup tuned liquid. The $\mathrm{Ar}$ and $\mathrm{Cl}$ ion disturbance had been eradicated by using standard interference correction equations of the instrument. We chose to measure ${ }^{82} \mathrm{Se}$ had due to less interference.

Quality control: measure the Se content in spinach GSB-6 and soil ESS-3 with reference material. Quality control was applied to the measurement method(see table 1).

Table 1 The determination results for reference material $(\mathrm{n}=11)$

\begin{tabular}{ccccc}
\hline $\begin{array}{c}\text { Standard } \\
\text { reference } \\
\text { materials }\end{array}$ & $\begin{array}{c}\text { Measure } \\
\text { d values } \\
(\mathrm{mg} / \mathrm{kg})\end{array}$ & $\begin{array}{c}\text { Standard } \\
\text { values } \\
(\mathrm{mg} / \mathrm{kg})\end{array}$ & $\begin{array}{c}\mathrm{RS} \\
\mathrm{D} \\
(\%)\end{array}$ & $\begin{array}{c}\text { The } \\
\text { relativ } \\
\text { error } \\
(\%)\end{array}$ \\
\hline $\begin{array}{c}\text { soil(ESS-3) } \\
\text { spinach(GS } \\
\text { B-6) }\end{array}$ & 0.0991 & $\begin{array}{c}0.092 \pm 0.0 \\
24\end{array}$ & 4.8 & 7.2 \\
\hline
\end{tabular}

\section{The measurement of heavy metals (Pd, Cd) content in samples}

Soil digestion: $0.2 \mathrm{~g}$ pre-treatment soil sample was put in the microwave digestion tank, $5 \mathrm{~mL}$ $\mathrm{HNO} 3,2 \mathrm{~mL} \mathrm{HCl}$ and $1 \mathrm{~mL} \mathrm{HF}$ were added, pre-digested for $3 \mathrm{~h}$, then the digestion process were conducted by using microwave digestion instrument. After the digestion process completed, at $150^{\circ} \mathrm{C}$ waited until it nearly desiccated, then added ultrapure water until the volume was $25 \mathrm{~mL}$.

Crops digestion: $0.2 \mathrm{~g}$ pre-treatment crop sample was put to microwave digestion tank, $8 \mathrm{~mL}$ $\mathrm{HNO}_{3}$ was added, pre-digested for $3 \mathrm{~h}$, then the digestion process were conducted by using microwave digestion instrument. After the digestion process completed, added $2 \mathrm{~mL}$ hydrogen peroxide, at $150^{\circ} \mathrm{C}$ waited until it nearly desiccated, then added ultrapure water until the volume was $25 \mathrm{~mL}$.

Method: FAAS (model SOLAAR M6) was used to measure the Pb content in the soil, GF-AAS (model TAS-990) was used to measure the Pb content in crops. ICP-MS (model NexIONTM300) was used to measure the $\mathrm{Cd}$ content in soil and crops. 
Quality control: FAAS was used to measure the $\mathrm{Pb}$ content in soil reference materials(GSS-4), the value was $57.74 \mathrm{mg} / \mathrm{kg}$ (standard value: $58 \pm 5 \mathrm{mg} / \mathrm{kg}$ ), RSD was $4.5 \%$, relative error were $0.5 \%$; FAAS was used to measure the $\mathrm{Pb}$ content in spinach reference materials(GSB-6), the value was $10.30 \mathrm{mg} / \mathrm{kg}$ ( standard value : $11.1 \pm 0.9 \mathrm{mg} / \mathrm{kg}$ ) RSD was $3.2 \%$, relative error was $7.2 \%$; GF-AAS was used to measure the Cd content in soil and spinach reference materials (GSS-4 and GSB-6). The value were $0.3760 \mathrm{mg} / \mathrm{kg}$ (standard value: $0.35 \pm 0.06 \mathrm{mg} / \mathrm{kg}$ ） and $0.1534 \mathrm{mg} / \mathrm{kg}$

( standard value: $0.150 \pm 0.025 \mathrm{mg} / \mathrm{kg}$ ) respectively, RSD was $4.1 \%$ and $4.2 \%$ respectively, relative error were $7.4 \%$ and $2.3 \%$ respectively.

\section{statistical analysis}

Correlation statistical analysis was conducted using statistical software IBM SPSS statistics19.0.

\section{The results and discussion}

\section{The distribution of Se in soil-crop systems in selenium-rich area}

36 kinds of crops were classified according to leaf vegetable species(15), melon and fruit(11), bean species(3), potato species(4), grain and oil species(3), the average measurement results of Se contents in crops are in table 2.

Table 2 Selenium content in a variety of crops and their planting soil ( unit: $\mathrm{mg} / \mathrm{kg}$ )

\begin{tabular}{cccccc}
$\begin{array}{c}\text { Selenium } \\
\text { content }\end{array}$ & $\begin{array}{c}\text { Leaf } \\
\text { vegetables }\end{array}$ & $\begin{array}{c}\text { Melon } \\
\text { fruits }\end{array}$ & Beans & Potatoes & $\begin{array}{c}\text { Grain } \\
\text { oils }\end{array}$ \\
\hline $\begin{array}{c}\text { In Planting } \\
\text { soils }\end{array}$ & 0.4412 & 0.4130 & 0.3519 & 0.3895 & 0.3250 \\
\hline $\begin{array}{c}\text { In crops } \\
\text { (dry } \\
\text { weight })\end{array}$ & 0.1035 & 0.0587 & 0.0483 & 0.0884 & 0.0655 \\
\hline $\begin{array}{c}\text { In crops } \\
\text { fresh } \\
\text { weight })\end{array}$ & 0.0161 & 0.0050 & 0.0117 & 0.0158 & 0.0472 \\
\hline
\end{tabular}

According to table 2, the Se content in crops (dry weight) were in the following order: leaf vegetable species $>$ potato species $>$ grain and oil species $>$ melon and fruit species $>$ bean species. The Se content in crops(fresh weight) were in the following order: grain and oil species $>$ leaf vegetable species $>$ potato species $>$ bean species $>$ melon and fruit species; The difference in moisture results in the ranking differences, grain and oil species contained less water, thus showed little effect on Se content. No matter the material was dry or fresh, leaf vegetable species topped the list of all materials in Se content. According to the newest selenium-rich food standard from Jiangxi province (table 3), leaf vegetable species (fresh weight) rank only No. 2 with Se content, but most of them are selenium-rich vegetables, the No. 1 with Se content (fresh weight) were grain and oil species, due to high Se content, only sesame belongs to selenium-rich food. We should compare the Se content standard in selenium-rich food with the Se content level in crops. According to what have mentioned above, leaf vegetable species would be the best choice to develop the selenium-rich agriculture products.

Table 3 Jiangxi Provincial Standard--Classification standards of selenium content in selenium-rich food (DBD36/T566-2009)

\begin{tabular}{cc||cc}
\hline Food & $\begin{array}{c}\text { Se Content } \\
(\mathrm{mg} / \mathrm{kg})\end{array}$ & $\begin{array}{c}\text { Food } \\
\text { Vegetable }\end{array}$ & $\begin{array}{c}\text { Se Content } \\
(\mathrm{mg} / \mathrm{kg})\end{array}$ \\
\hline $\begin{array}{c}\text { Rice and } \\
\text { its } \\
\text { products }\end{array}$ & $0.07 \sim 0.30$ & $\begin{array}{c}\text { (potatoes }) \\
\text { Bean and } \\
\text { its }\end{array}$ & $0.07 \sim 0.10$ \\
$\begin{array}{c}\text { products } \\
\begin{array}{c}\text { Peanut } \\
\text { and its } \\
\text { products }\end{array}\end{array}$ & $0.07 \sim 0.30$ & $\begin{array}{c}\text { and its } \\
\text { products }\end{array}$ & $0.01 \sim 0.05$ \\
\hline
\end{tabular}




\section{Crops Se enrichment effect from planting soil}

The element contained in plant mainly come from its planting soil. Generally, bioconcentration factors $(\mathrm{BCF})$ were used to illustrate the degree of element enrichment from soil to plant. Here is the formula:

$\mathrm{BCF}=\mathrm{C}_{\text {plant }} / \mathrm{C}_{\text {soil }}$

$\mathrm{C}_{\text {plant }}$ represents the content of element in plant (dry weight), $\mathrm{C}_{\text {soil }}$ represents the content of element in planting soil. Based on the BCF value, elements could be classified into some certain bioconcentration sequence. Using Table 2, we calculated the BFC of all collected crops, the results showed in Table 4.

Table 4 A variety of crops BCF for selenium in their planting soil

\begin{tabular}{cccccc}
\hline $\begin{array}{c}\text { Selenium } \\
\text { content }\end{array}$ & $\begin{array}{c}\text { Leaf } \\
\text { vegetables }\end{array}$ & $\begin{array}{c}\text { Melon } \\
\text { fruits }\end{array}$ & Beans & Potatoes & $\begin{array}{c}\text { Grain } \\
\text { oils }\end{array}$ \\
\hline $\begin{array}{c}\text { The } \\
\begin{array}{c}\text { enrichment } \\
\text { coefficient } \\
\text { (BCF) }\end{array}\end{array}$ & 0.235 & 0.142 & 0.137 & 0.227 & 0.202 \\
\hline
\end{tabular}

According to Table 4, Se is the middle level enriched element for crops ${ }^{[4]}$, the BFC ranging from $0.137-0.235$. The selenium enrichment ability of different crops: leaf vegetable species $\geq$ potato species $>$ grain and oil species $>$ melon and fruit species $\geq$ bean species. This showed that leaf vegetable species have strongest Se enrichment ability. After comparing the BCF of Se in crops of 15 different leaf vegetable species (See Figure 1), it is cleared that leaf vegetable species enriched more selenium than other species. Except The garlic sprout, cabbage, Chinese cabbage and shallot whose BFC are smaller than 0.2, the BFC of all other leaf vegetable species were higher than 0.2. The highest BFC was above 0.5. The BCF value illustrates the role and degree of impact of soil element to plant. Thus, choosing the crops which have strong ability to enrich selenium and using planting soil which contains higher selenium content are the direct way to produce selenium-rich agriculture products. According to what have mentioned above, in selenium-rich area of Haikou, leaf vegetable species should be selected as a priority for the development of selenium-rich agricultural products, especially lettuce, mustard, pakchoi, senvy and pamphrey.

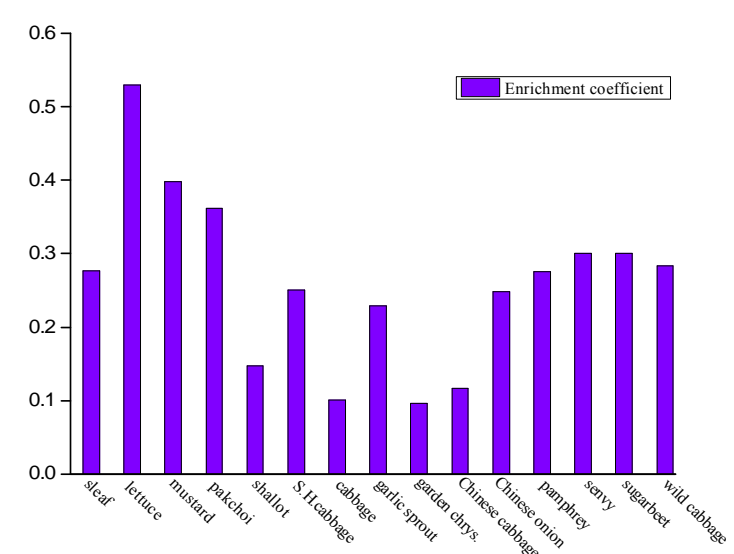

Figure $1 \mathrm{BCF}$ of Se in crops of leaf vegetable species

\section{The effects of Se content in soil on heavy metals enrichment $(\mathrm{Pb}, \mathrm{Cd})$ of selenium-rich soil}

The mass fraction of $\mathrm{Se} \geq 0.4 \mathrm{mg} / \mathrm{kg}$ soil was called selenium-rich soil. 37 selenium-rich soil samples were chosen from the gathered crops planting soil samples. The element contents were as follows: Se $0.5088 \pm 0.1115(0.4002 \sim 0.9500) \mathrm{mg} / \mathrm{kg}, \mathrm{Pb} 26.59 \pm 14.56(3.361 \sim 67.02) \mathrm{mg} / \mathrm{kg}, \mathrm{Cd}$ $0.3792 \pm 0.2697(0.1502 \sim 1.137) \mathrm{mg} / \mathrm{kg}$. Using SPSS to analyze the correlation between $\mathrm{Se}$ and $\mathrm{Pb}$, Cd. See table 5.

Table 5 The correlation between contents of $\mathrm{Pb} \mathrm{Cd}$ with Se in the Se-rich soil $(\mathrm{N}=37)$

\begin{tabular}{ccc}
\multicolumn{3}{c}{ with Se in the Se-rich soil $(\mathrm{N}=37)$} \\
\hline $\begin{array}{c}\text { The correlation } \\
\text { coefficient }\end{array}$ & Se and Pb & Se and Cd \\
\hline
\end{tabular}

note: *means it is significant on 0.05 level 
From the table above, we can see that $\mathrm{Se}$ content is positive correlated with $\mathrm{Pb}, \mathrm{Cd}$. $\mathrm{Se}$ and $\mathrm{Cd}$ is positive correlated on 0.05 level. The table shows that $\mathrm{Se}$ has associated effects with $\mathrm{Pb}, \mathrm{Cd}$ to a certain extent. And the associated effect between Se and Cd was more significant.

\section{The effects of the selenium content in soil on heavy metal ( $\mathrm{Pb}$ and $\mathrm{Cd}$ ) enrichment in leaf vegetable species}

Leaf vegetable species like brassica juncea and cabbage are wildly planted, they also have similar Se enrichment charateristics and moisture content. Here we used 8 brassica juncea and 10 cabbage from the Se rich region as research sample objects to study the effects of the selenium content in soil on heavy metal $(\mathrm{Pb}$ and $\mathrm{Cd}$ ) enrichment in leaf vegetable species. By using SPSS software analysis tool, we analyze the above samples the effects of the selenium content in soil on heavy metal $(\mathrm{Pb}$ and $\mathrm{Cd})$ enrichment in crops (brassica juncea and cabbage). The results are in Table 6.

\begin{tabular}{|c|c|c|}
\hline & $\begin{array}{c}\mathrm{Se} \text { and } \\
\mathrm{Pb}\end{array}$ & $\begin{array}{c}\text { Se and } \\
\text { Cd }\end{array}$ \\
\hline $\begin{array}{l}\text { The correlation coefficient } \\
\text { with content in crops }\end{array}$ & -0.274 & 0.022 \\
\hline $\begin{array}{l}\text { The correlation coefficient } \\
\text { with enrichment coefficient }\end{array}$ & -0.245 & 0.080 \\
\hline
\end{tabular}

note: *means it is significant on 0.05 level

From above table, we can see that the correlation between $\mathrm{Pb}, \mathrm{Cd}$ contents in crops or $\mathrm{BCF}$ of $\mathrm{Pb}, \mathrm{Cd}$ in crops( Cabbage and Brassica juncea) with contents of $\mathrm{Se}$ in the planting soil are not significant correlated. The $\mathrm{Pb}$ content in soil showed negative correlation with crops, so does BCF of $\mathrm{Pb}$ in crops. The affection degree are close.

It shows that Se content in the soil have the Antagonistic effect on the enrichment of $\mathrm{Pb}$. The Se in the soil showed positive correlation with Cd content or enrichment parameter (BCF) of the crops. The Se in the soil has greater effect on the enrichment parameter (BCF). Se content in the soil shows some synergistic effect on Cd content in crops. Thus, the Se content in soil had no significant effect on heavy metal enrichment, and showed different effects on different heavy metals. The relevant impact mechanism needs further study

\section{Acknowledgements}

This work was financially supported by the Natural Science Foundation of Hainan Province (214016), Scientific Research Foundation of the Higher Education Institutions of Hainan Province (Hjkj2013-01), and Scientific Research Special Foundation of the Higher Education Institutions of Hainan Province (Hnkyzx2014-01).

\section{References}

[1]Taylor J B, Marchello M J, Finley J W, et al. Nutritive value and display-life attributes of selenium-enriched beef-muscle foods [J]. Journal of Food Composition and Analysis, 2008, 21: 183-186.

[2]Zhang Yunqiang,MaoDeling. Fuzzy comprehensive evaluation of heavy-metals polluted degree for selenium-rich vegetable soil in Jin HuaCity[J].Hunan Agricultural Sciences,2012,(01):47-49.(in Chinese)

[3]Xiao Yujie, LuoShengxu, WangYajuan, et al. Enrichment of $\mathrm{Se}, \mathrm{Cd}, \mathrm{Pb}$ in vegetables in Chengmai and the effects of Se [J]. Environmental Science \& Technology, 2014, 37 (8) : 76-79. [4]Yang-yang He, Sheng-xuLuo, Hui Yan, Yu-jie Xiao, Yang Yu. Study on the Phytoavailability of heavy metal lead, copper, zinc in Ilex kudingcha C. J. Tseng soil. Advanced Materials Research,Vols. 807-809 (2013),pp144-148. 
